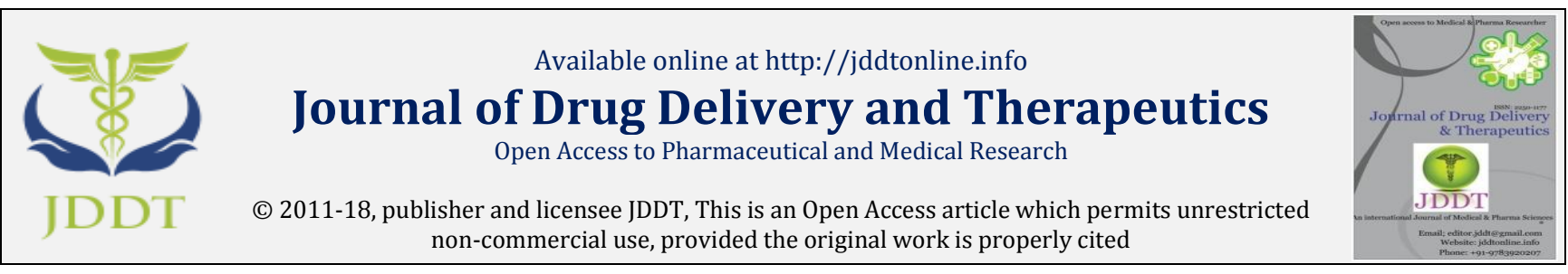

Open 2 Access

Review Article

\title{
Overview on virosomes as a novel carrier for drug delivery
}

\author{
Dr. Shaikh Siraj N*, Shahid Raza, Mohd. Aslam Ansari, Dr. G.J. Khan, Siddiqi Hifzurrahman MD Athar \\ Department of Pharmaceutics, Ali-Allana College of Pharmacy Akkalkuwa, Dist. Nandurbar, Maharashtra, India-425415
}

\begin{abstract}
As from the last eras number of the revolution in the drug delivery technologies have been seen to attain the targeted drug delivery or site specific action of the drug. The prospects of the drug delivery by using biomimetic nanoparticles such as virosomes is an motivating research \& development field as showing targeted action by fusion with the targeted action by fusion through target cell. It can be engaged as vehicle $\&$ vaccines furthermore victory of virosomal drug delivery depends on the method used to make the encapsulated bioactive materials, characterization \& formulation of finished products. They are reconstituted viral envelopes that can be conveyance of different macromolecules as these are biocompatible, biodegradable, nonautoimmunogenic. Virosomes denotes such a unique system for presentation of antigen to immune system. Peptides, nucliecacid \& medications such as antitoxins, anticancer agents \&steroids can be encapsulated. This review focus on various aspects of Virosomes, such as Structure of Virosomes Component, Advantages, disadvantages, Method of preparation, Characterization, recent Patents and applications of Virosomes etc.
\end{abstract}

Key words: Neurodegenerative, Nonimmunogenic, Endolysosomal, Cryoprotectants, Applications.

Article Info: Received 05 Nov, 2018; Review Completed 23 Dec 2018; Accepted 28 Dec 2018; Available online 01 Jan 2019

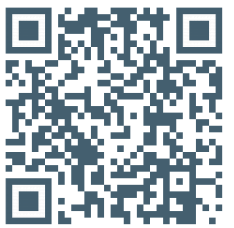

Cite this article as:

Shaikh SN, Raza S, Ansari MA, Khan GJ, Athar GHMD, Overview on virosomes as a novel carrier for drug delivery, Journal of Drug Delivery and Therapeutics. 2018; 8(6-s):429-434 D0I: http://dx.doi.org/10.22270/jddt.v8i6-s.2163

\section{*Address for Correspondence:}

Maharashtra, India.

Dr. Shaikh Siraj N, Head Department of Pharmaceutics, Ali-Allana College of Pharmacy Akkalkuwa, Dist. Nandurbar,

\section{INTRODUCTION}

One of the causes of stoppage of the promising drug during development is failure to deliver to the target cell, tissue \& organ 1,2 . The novel therapeutics includes the delivery that targets the drug to the particular cell \& tissue by controlled release \& receptor mediated uptake ${ }^{3}$. Furthermore the new generation of the therapeutics especially against cancer or neurogenerative disorders desires delivery system which target the drug to the host cell \& tissue 4.Virosomal technology is developed in order to overcome the difficulty of incomplete delivery to the targetting cell, tissue \& organs of the body ${ }^{5}$.virosomes have become talentedcandidate for the targetting the drug \& antigen delivery ${ }^{6}$. As novel drug delivery technology should deliver improved bioavailability $\&$ should reduce the dose of the drug, during the clinical test several drugs fails due to the lack of delivery technology. The prospect of drug delivery \& targetting using virosomes is an interesting field of research \& development 7 . Virosomal technology grants a novel sophisticated delivery system to meet the challenges of targeting to the cell \& tissues; these are lipoidal biocarrier for site specific targetting ${ }^{8}$. Virosome is reconstituted viral envelope includes lipids membrane \& viral spike glycoprotein but lacking of viral genetic materials, virosomes first primed by Almeida et al. by inserting purified influenza spike proteins into preformed liposomes. Thereafter a variety of viral envelops have been reconstituted including Sendai virus, Semliki forest virus \& Sindbis virus. Virosomes shows viral envelop of glycoprotein \& their native conformation stimulates humoral responses. Sendai virus virosomes generated by reconstitution of Sendai fusion protein ${ }^{9,10}$. In short Virosomes are regenerate empty influenza virus envelopes where infectious nucleocapside be substituted by compound of choice as they having pure fusion activity thus deliver the incorporated compounds to or inside the target cells, in this compounds like drug, antigen, genes can be incorporated. One of major advantage which is the object of great interest of using virosomes as guards the incorporated compounds from proteolytic degradation \& low $\mathrm{pH}$ within the endosomes as permits their content to remain intact while it reaches to the cytoplasm. Furthermore achievement of virosomal drug delivery depends on the technique used to prepare the encapsulated bioactive materials, characterisation \& formulation of finished products. As virosomes are biodegradable, biocompatible, nontoxic \& nonautoimmunogenic attempts were made to use them as a vaccines or adjuvants as well as delivery system for drug, nucleic acid, gene for therapeutic application ${ }^{11}$.

\section{I) STRUCTURE OF VIROSOMES}

-Virosomes are semi-synthetic sphere-shaped or unilamellar complex derived from nucleic acid free viral particles, bilayer 
vesicle mean diameter size ranges from 120-180 nm. Composed of lipid bilayer in which inserted viral glycoproteins are derivative from different enveloped virus. Virosomes are created by dissolving the envelop of a virus by detergent then viral membrane is reconstituted \& produces virosome containing viral membrane proteins \& lipids. Essentially Virosomes signifies reconstituted empty influenza virus envelops devoid of the nucleocapside with the genetic material of source virus. Influenza virus is most frequently used for virosomes production \& genetic material of the source virus. The chief constitute of immune stimulating regenerate Influenza virosomes contain of naturally occurring Phosphatidyl choline (PC) \& Phospholipids (PL), PC forms around $70 \%$ of the virosomal assembly \& remaining $30 \%$ of membrane components are enclose phospholipids which originates from influenza virus containing the glycoproteins intercalated inside the phospholipid bilayer membrane \& these glycoproteins are Neuraminidase (NA) \& Haemagglutinin (HA) glycoproteins ${ }^{12}$. In distinction to liposomes, virosomes can be capable by intrinsic immunogenic properties functioning both the carrier \& adjuvant that can be capable to deliver the antigen \& stimulates immune cells simultaneously. HA \& NA proteins of virosomesenables efficient vesicle uptake by later activation of cells of immune system. NA is a tetramer composed of 4 equal spherical subunits hydrophobically embedded in Immunostimulating Reconstituted Influenza Virosomes (IRIV) membrane by a central stalk \& that readily intercalates into phospholipid membrane \& involved in budding ${ }^{13}$. NA present on IRIV's exterior aids the action by the same mechanism through which it enhances influenza virus pathogenicity it catalyses the breakdown of $\mathrm{N}$ acetylneuraminic acid from bound sugar residue leads to decrease viscosity of host's mucus permitting to the influenza virus an easier entree to epithelial cells, the same procedure leads to demolition of HA receptors within cell membrane to which viruses \& IRIV's binds. This allows virus particle to avoid aggregation as newly formed virus particle do not adhere to infected host cell membrane after budding. The mode of action of IRIV's is dependent on the influenza haemagglutinin which is intercalated into the phospholipidbilayer \&steadies the liposomes bases by preventing fusion with other liposomes. HA is major influenza antigen which is formed from two polypeptides HA1\& HA2 which are involved in receptor binding \& membrane fusion.

HA1- Globular head contain a receptor site that has a high affinity for sialic acid present on antigen presenting cell (APC's) surface like lymphocytes \& macrophages.

HA2- The fusion of IRIV's with endosomal membrane is then mediated by HA2 polypeptide ${ }^{14}$.
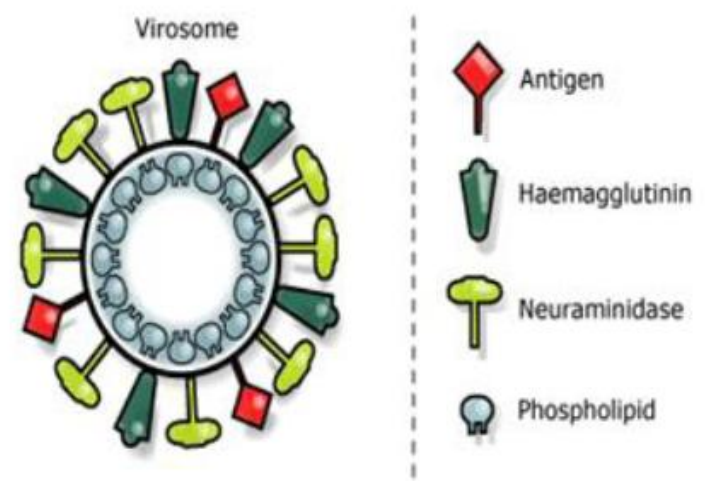

Figure 1: Different component of Virosomes

\section{II) RATIONALE FOR USING AND DEVELOPING VIROSOMES}

- Solubilization of poorly water soluble drugs: diazepam, vitamin A, dexamethasone palmitate.

- Site specific delivery to various organs: cytotoxic agents.

- Potential for sustained release dosage forms dexamethasone palmitate, barbiturates, physostigmine salicylate ${ }^{15}$.

\section{III) ADVANTAGES OF VIROSOMES}

- This technology is approved by FDA for use in human \& has proven to have safety profile.

- Completely biodegradable, Biocompatible \& nontoxic.

- No risk of disease transmission, no auto immunogenicity.

- Enables delivery of drug to conveyance into cytoplasm of target cell.

- Defends drug against degradation.

- Promotes combination movement in the endolysosomal pathway.

- Controlled by either injection or nasally.

- Allows tolerant specific modular vaccine regimes.

- Up scaling according to standard procedure possible.

- Virus like structures provides repetitive antigen presentation to B cells \& mimics natural intracellular processing of the antigen that leads to stimulation of both arms of immune system, humoral \& cellular immune responses.

- The antigen is incompletely protected from extracellular degradation \& the resulting depot effect greatly facilitates immune potentiation.

- Extended uptake, distribution \&elimination of drug in the body.

- High quality \& long lasting antibody responses.

- Excellent safety profile.

- Conformational stabilization of antigen.

- They can be largely applied with almost all forms of drugs (Anticancer drugs, Antibiotics \& fungicides) small organic molecules like proteins, peptides \& nucleic acids.

- Appropriate for elderly \&infants 16 .

\section{IV) DISADVANTAGES OF VIROSOMES}

- They might induce immune responses since they often have viral glycoprotein on the surface.

- Rapid disintegration in the blood compartment is potential issue connected with virosomes,

- Short shelf life.

- Manufacturing problems.

- Poor quality of raw materials.

- Pay load is too slow.

- Non availability of data related to chronic use of virosomes. 
- Rapid disintegration can be overcome by growing the stability of virosomes or making virosomes reaches targetting sites inside a short time after administration ${ }^{16}$.

- Use of high quality products with improved purification protocols.

- Quality control assay can be made by using sophisticated instruments $\&$ batch to batch variability can be checked.

- Use of remote loading techniques to overcome payload problems.

- Improvement in shelf life using appropriate cryoprotectants \& lyoprotectants.

- Scale up problems can be enhanced by selection of proper method of preparation \& sterilization by autoclaving or membrane filtration coupled with aseptic $\&$ validated pyrogen removal Lal test.

- By selecting drugs with narrow therapeutic index 17,18 .

\section{V) METHOD OF PREPARATION OF VIROSOMES}

1. Selection of virus for virosomes- Virosomes are reconstructed viral envelope that can be derived from different virus. Influenza virus envelope is most commonly used to produce virosome but virosome can also be made from other unlike types of viruses also such as Sendai virus, Epstein-burr virus, HIV, sindbis, semlikiforest virus, friend murine leukaemia virus, herpes simplex virus, Newcastle disease virus.

2. Selection of antigen- Depending on the necessities antigens are selected. Antigens which are used like a bacteria parasite, carcinogenic cell, or whole cell is used as antigens. Cell components include RNA, DNA, or plasmid could also be used as antigen. This antigen is coupled to lipid anchor so antigen will be ready to load on virosomes.

- Reconstitution of Virosomes- Virosome solubilised with detergent like octaglucoside, triton $\mathrm{x}-100$, nonidert p-40 Due to solubilization with detergent internal viral protein and genetic material will residue then detergent is removed by dissimilar method such as dialysis and hydrobhobic resins from supernatant. By using ultracentrifugation process viral matrix protein and nucleicapsid is removed. Viral phospholipid (82\%) and viral protein is recovered in supernatent. Now antigen which is coupled to lipid anchor is mixed with polymer or surfactant solution and this solution is processed with virosome carrier so that antigen bound virosome is obtained 17,18

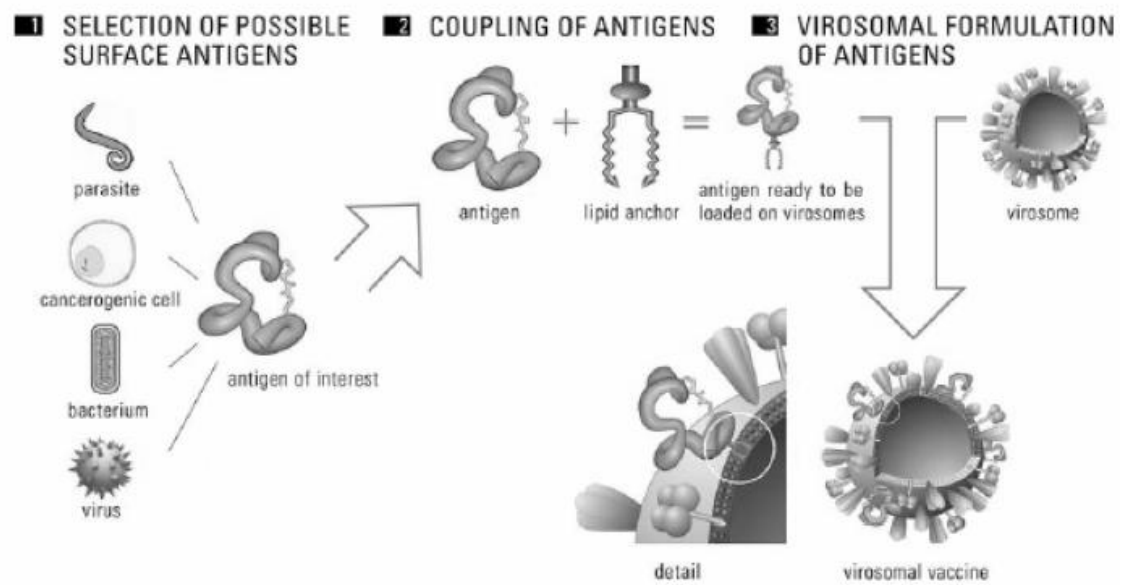

Figure 2: General method for preparation of virosomes

\section{VI) CHARACTERIZATION OF VIROSOMES}

1. Detection of protein- Virosomal preparation should result in a uniform protein to lipid ratio, presence of haemagglutinin protein on virosomes can be confirmed by Sodium dodecyl sulfate polyacrylamide gel electrophoresis (SDS-PAGE).

2. Fusion activity- Generally virosomes displays $\mathrm{pH}$ dependent film combination movement like local flu infection similar to native influenza virus, Fluorescent resonance energy transfer assay is used to visualized the virosomal fusion with artificial \& biological target membrane fusion can be assessed in vitro with excimer virosomal combination with organic or counterfeit target film can be surveyed in vitro to measure utilizing pyrene-named lipid where decrease of surface density of pyrene- Phosphatidylcholine label on fusion with unlabelled membrane leads to decrease in fluorescence.
3. Structure \& size-Negative-stain electron microscopy generally used to determine ultrastructure and size of virosomes. The staining solution is of neutral $\mathrm{pH}$, to avoid acid-induced conformational changes of HA.

\section{VII) MECHANISM OF ACTION OF VIROSOMES}

Virosomes operates together as a carrier \& as the adjuvants with dissimilar types of functions for induction of immune responses, the carrier function involves the embedding of antigens into virosomes particles that gives the positive effect integration of antigen stability the antigen on surface of virosomes mimics the original pathogen \& generates the antibodies. Induction of antigen on surface immunizes by creating the B cells such form complex are main focus for targetting immune cells which is important for induction of immunity.

The adjuvant function relates to stimulation of immune properties of virosomes \& components of immune system without causing nonspecific inflammation, adjuvant function is based on the presence of haemagglutinin pre-existing 
antibodies against influenza bind to virosomes leads to rapid uptake \& processing by Antigen presenting cells (APC). The natural function of antibody to bind virus \& block infection, one of the factors to make virosomal particle attractive target for uptake \& processing by immune cell, is the size \& surface of virosomes which is important for initiating immune response. APC activates pre-existing influenza specific helper $\mathrm{T}$ cell activated helper cells proliferates \& secretes cytokines for stimulating immune cells 19 .

\section{VIII) ROUTE OF ADMINISTRATION OF VIROSOMES}

They can be administered by ranges of routes including intravenous (IV), intramuscular (IM), subcutaneous (SC), intra-arterial \& Inhalable delivery also by topically, orally \& transdermally. Equipped virosomes suspended in saline buffer $(135-150 \mathrm{~mm} \mathrm{NaCl})$, sterilized by conventional liposomal sterilization method such as membrane filtration. To mimic physiological status they need to contain auxiliary substances such as buffering agents \& isotonicity regulating agent like Calcium chloride, Sodium lactate, Sodium acetate, Sodium chloride. The concentration of virosomes used in the vehicle ranges from $20-200 \mathrm{mg} / \mathrm{ml}$, however it can optimized depending on the requirement for the purpose. The virosomes can be incorporated into implantable devices for long term therapy release.

\section{IX) EVALUATION OF VIROSOMES}

$\checkmark$ Protein detection-Relatively uniform protein to lipid ratio is observed in prepared virosomes. To confirm the presence of HA protein, Sodium dodecyl sulfatepolyacrylamide gel electrophoresis (SDS- PAGE) method is used.

$\checkmark \quad$ Surface charge- Free flow electrophoresis.

$\checkmark \quad$ Structure \& size- Negative stain electron microscopy with neutral staining agents is used, determined by photo correlation spectroscopy, transmission electron microscopy, dynamic light scattering, and gel permeation \& gel exclusion techniques.

$\checkmark$ Lamellarity- It can be determined 13p-NMR, Freeze fracture electron microscopy.

$\checkmark$ Percent free drugs- It can be determined by mini column centrifugation, gel exclusion, radiolabel ling, protamine aggregation.

$\checkmark$ Phase behaviour- Differential scanning colorimetry, freeze fracture electron microscopy.

$\checkmark \quad$ Drug release- Diffusion cell dialysis

$\checkmark$ Animal toxicity- It can be determined by monitoring history, pathology \& survival rates.

$\checkmark$ Pyrogenicity- It can be determined by Rabbit fever test, Limulus ambeocyte lysate (LAL) test.

$\checkmark$ Surface chemical analysis- Static secondary ion mass spectrometry.

\section{X) PHARMACOKINETIC OF VIROSOMES}

Information regarding differences in the pharmacological effect of free drug \& encapsulated drug can be given by the pharmacokinetic studies that help in dose designing; it can give the information regarding the absorption, distribution \& degradation time course of retention, dissemination \& debasement of the virosomal transport in-vivo. Effect of pharmacokinetic parameter on virosomes shown following outcomes-

- Greater therapeutic index.
- Greater concentration at targeted sites.

- Protection of drug in plasma.

- Decrease in toxicity\& nonspecific reaction.

- $\quad$ Reduction in nonspecific localization. 20.

\section{XI) APPLICATIONS OF VIROSOMES}

- Virosomes coupled to the antibody to improve the tissue specificity as antibody binds to the specific receptor a number of the virosomes based product have been approved by USFDA for human use. The main properties involves in the virosomal design is interaction between antigenic proteins of the virus \& cellular receptors. The virosomal receptor interaction investigated for treating the parasitic disease, viral disease, neurological disease \& other metabolic disorders.

- Virosomes containing antibacterial, antimalarial, antifungal have shown effective Invitro \& in vivo profile, the virosomes based sedates conveyance is in any case, quick, sheltered \& viable rather than other related system.

- $\quad$ Apart from this virosomes can also delivers proteins \& peptides eg- gelonin subunit A of diphtheria toxin has been delivered to target cells by virosomes as well as ovalbumin.

- $\quad$ Cancer treatment - Cancer is one of the major health issue worldwide still it remains great challenges as having potential application of NDDS in cancer therapy enabled the development of the novel therapeutic strategies.

Virosomes also used in the oncology field as they can carry peptides to tumor associated antigens, peptides corresponding to Tumor Associated Antigens(TAA) as in case of peptides derived from the parathyroid hormone related protein (PTH-rp) or from recombinant protein such as Her-2/neu, Fab combined the anti-proliferate properties of monoclonal antibodies \& cytotoxic effect of doxorubicin in vivo.

- Gene delivery- Haemagglutinin the membrane fusion protein of influenza virus known to mediate the low $\mathrm{pH}$ dependent fusion reaction between the viral envelop \& limiting membrane of the endosomal cell compartment which follow cellular uptake of virus particle by receptor mediated endocytosis.

- Malaria therapy- Virosomes shows good tolerability \& highly specific immune responses it has been identified two peptides structures serving as antigens for malaria vaccines. The NPNA regions of circumsporozoite protein (CSP) loop I of domain III of merozoites apical membrane antigen-1 (AMA-1) that leads additional structural antigens that identified.

- Immune stimulation - Virosomes provides pathogenassociated molecular pattern (PAMP) that that gives stimulatory signals to APC.

- RNA/DNA delivery-Genetic materials encapsulated in virosomes are able to put adequate synthesis of newly induced expressed proteins overcoming lack of suitable delivery method for these molecules Intraperitoneal injection of SiRNA loaded virosomes resulted in delivery of nucleotide to peritoneal cell 21 . 
Table 1: First generation Virosomes ${ }^{22}$

\begin{tabular}{|c|c|c|}
\hline Products & Indication & Vaccine composition \\
\hline Epaxal ${ }^{\circledR}$ & $\begin{array}{c}\text { Hepatitis A } \\
\text { Adult }\end{array}$ & $\begin{array}{c}\mathrm{A}(\mathrm{H} 1 \mathrm{~N} \text { 1) virosomes \& inactivated Hepatitis A } \\
\text { virus }\end{array}$ \\
\hline Inflexal ${ }^{\circledR}$ & $\begin{array}{c}\text { Seasonal Influenza } \\
\text { All age groups }\end{array}$ & $\begin{array}{c}\text { Virosomes from 3 Influenza strains A(H1N1), } \\
\mathrm{A}(\mathrm{H} 3 \mathrm{~N} 3), \mathrm{B}\end{array}$ \\
\hline Nasalflu $^{\circledR}$ & $\begin{array}{c}\text { Seasonal Influenza } \\
\text { Intranasal application }\end{array}$ & $\begin{array}{c}\text { Virosomes from 3 Influenza strains } \\
\mathrm{A}(\mathrm{H} 1 \mathrm{~N} 1), \mathrm{A}(\mathrm{H} 3 \mathrm{~N} 2), \mathrm{B} \& \text { HLT adjuvant }\end{array}$ \\
\hline Invivac $^{\circledR}$ & Seasonal Influenza & $\begin{array}{c}\text { Virosomes from 3 Influenza strains } \\
\mathrm{A}(\mathrm{H} 1 \mathrm{~N} 1), \mathrm{A}(\mathrm{H} 3 \mathrm{~N} \text { 2)B }\end{array}$ \\
\hline Epaxal ${ }^{\circledR}$ Junior & $\begin{array}{c}\text { Hepatitis A } \\
\text { child }\end{array}$ & $\begin{array}{c}\mathrm{A}(\mathrm{H} 1 \mathrm{~N} 1) \text { virosomes \& inactivated Hepatitis A } \\
\text { virus }\end{array}$ \\
\hline
\end{tabular}

Table 2: Second generation Virosomes(22)

\begin{tabular}{|c|c|c|}
\hline Disease, target, effector & Antigen configuration & Administration Route \\
\hline $\begin{array}{c}\text { HIV } 41 \\
\text { antibody }\end{array}$ & 1 Peptide membrane-anchored & $\begin{array}{c}\text { Intramuscular prime \& intranasal } \\
\text { boost }\end{array}$ \\
\hline $\begin{array}{c}\text { Malaria } \\
\text { Plasmodium falciparum } \\
\text { AMA-1 \& CSP antibody }\end{array}$ & 2 peptides membrane-anchored & Intramuscular \\
\hline $\begin{array}{c}\text { Breast cancer } \\
\text { Her2/neu } \\
\text { antibody }\end{array}$ & 3 peptides membrane-anchored & Intramuscular \\
\hline
\end{tabular}

Table 3: Marketed Products of Virosomal drug delivery (22)

\begin{tabular}{|c|c|c|}
\hline S. No. & Virosomal preparations & Application \\
\hline A & \multicolumn{2}{|c|}{ Virosomes antigen based products } \\
\hline 1 & $\begin{array}{c}\text { 1 Hepatitis A virus envelope proteins } \\
\text { (EpaxalW) }\end{array}$ & Hepatitis a \\
\hline 2 & Influenza virus (InflexalW V) & Influenza \\
\hline B & $\begin{array}{c}\text { Virosomal antigen preparations } \\
\text { under clinical trials }\end{array}$ \\
\hline 1 & $\begin{array}{c}\text { Diphtheria/tetanus toxoid virus envelope } \\
\text { proteins }\end{array}$ & Diphtheria, Tetanus \\
\hline 2 & $\begin{array}{c}\text { Peptidomimetic of loop I from domain III of } \\
\text { Plasmodium falciparum AMA-1 }\end{array}$ \\
\hline 3 & PEV6 & Breast cancer \\
\hline C & Virosomal antigen preparations under pre-clinical trials \\
\hline 1 & Doxorubicin & Cancer \\
\hline 2 & Doxorubicin & Cvarian carcinoma \\
\hline 3 & L-myc antisense ODNs & Carcinoma \\
\hline 4 & DNA-encoded TAA Prostate & Mumps \\
\hline 5 & DNA-encoded mumps antigen & \\
\hline
\end{tabular}

Table 4: Recent US Patents Of Virosomal Drug Delivery 22

\begin{tabular}{|l|c|c|}
\hline Sr.No. & US Patent No. & Title \\
\hline 1 & 7576066 & Nucleic acid compositions for stimulating immune responses \\
\hline 2 & 7615227 & Use of CpG oligodeoxynucleotides to induce angiogenesis \\
\hline 3 & 7615377 & Fluorescein-based metal sensors \\
\hline 4 & 7615539 & Nucleic acid-lipophilic conjugates \\
\hline 5 & 7618641 & Functionally reconstituted viral membranes containing adjuvant \\
\hline
\end{tabular}

\section{XII) CONCLUSION}

Virosomes represents an innovative novel drug delivery system for various biologically active molecules including nucleic acid \& genes for different purpose, they are safe, completely biocompatible, and biodegradable their surface can be modified to facilitate targeted drug delivery. They can be delivered to the host body through altered routes like intranasal, intradermal, and intramuscular depending on the aim of immunization. Tissue targetting immune activation \& potentiation are the chief advantages that making them efficient prophylactic \& therapeutic agent, they can be exploited as carrier for targeted drugs \& for immunomodulating molecules particularly in cancer therapy, Influenza virus considered as promising model for antigen \& unrelated molecules delivery that could be helpful for development of new vaccines.Appication of Virosome in drug delivery will bring a new prospective \& also open a new era in the modern pharmaceutical field $\&$ also human life too. 


\section{REFERENCES}

1. Kalra N, Dhanya V, Saini V, Jeyabalan G. Virosomes: As a Drug Delivery Carrier. American Journal of Advanced Drug Delivery 2013; 1(1):29-35.

2. Gaurav B, Manisha K, Vilasrao K. Virosome - drug and vaccine delivery system. World Journal of Pharmacy and Pharmaceutical Sciences 2014; 3(10):437-447.

3. Singh N, Gautam S, Kumari N, Kaur R, Kaur M. Virosomes as Novel drug delivery System: An Overview. Pharma Tutor 2017; 5(9):47-55.

4. Patel S.S, Patel M.J, Patel N.M. Need, Development and application of Virosomal system in medicine. International Journal of Pharmaceutical Sciences and Nanotechnology 2010 3(3):1065-1074.

5. Idris N, Chilkawar R, Nanjwade B, Srichana T, Shafioul A. Nanotechnology Based Virosomal Drug Delivery Systems. Journal of Nanotechnology and Materials Science 2014; 1(1):2735.

6. Babar MM, Zaidi N, Kazi A, Rehman. A Virosomes-Hybrid Drug Delivery Systems. Antivirals \& Antiretrovirals 2013; 5(7):166172.

7. Gowtham M, Pulak M, Krishnakumar KK. Virosomes: A Novel strategy for delivery of drugs and targeting: An overview. Journal of Pharmaceutical and scientific innovation 2012; 1(5):31-35.

8. Kamboj S, Saini V, Magon N, Bala S, Jhawat V. Vesicular drug delivery systems: A novel approach for drug targeting. International Journal of Drug Delivery 2013; 5 (2):121-130.

9. Lee S, Nguyen MT. Recent Advances of Vaccine Adjuvants for Infectious Diseases. Immune network 2015; 15(2):51-57.

10. Daemen T, Mare A, Bungener L, Jonge J, Huckriede A, Wilschut J. Virosomes for antigen and DNA delivery. Advanced Drug Delivery Reviews 2005; 57:451-463.
11. Martinho N, Damge C, Reis C. Recent Advances in Drug Delivery Systems. Journal of Biomaterials and Nanobiotechnology 2011; 2:510-526.

12. Inamdar N, Pulgamwar G, Jadhav K. Virosomes: New Frontier for Targetting Drug and biological molecules. Asian journal of Pharmaceutical technology \& Innovation 2015; 3(12):92-103.

13. Rebecca A, Amacker M, Moser C, Fabian B, Garnier C. Pulmonary Delivery of Virosome-Bound Antigen Enhances Antigen-Specific CD4+ T Cell Proliferation Compared to Liposome-Bound or Soluble Antigen. Pulmonary Immune Modulation by Virosomes 2017; 8:1-16.

14. Cusi M, Applications of Influenza Virosomes as a Delivery System. Human Vaccines. 2006; 2(1):1-7.

15. Sharma R, Yasir M. Virosomes: A Novel Carrier for Drug Delivery. International journal of Pharma Tech Research.2010; 2(4):23272339.

16. Liu H.Virosome, a hybrid vehicle for efficient and safe drug delivery and its emerging application in cancer treatment. Acta Pharm. 2015; 64:105-116.

17. Kumari A, Singla R, Guliani A, Yadav SK. Nanoencapsulation for Drug Delivery. EXCLI Journal 2014; 13:265-286.

18. Kapoor D, Vyas RB, Lad C, Patel M. Amultipurpose and novel carrier for drug delivery and targeting virosomes. Journal of Drug Delivery \& Therapeutics 2013; 3(5):143-147.

19. Rathore P, Swami G. Virosomes: a novel vaccination technology. IJPSR 2012; Vol. 3(10):3591-3597.

20. Sen R, Gupta R, Singh S, Mantry S, Das S. A Review on Cubosome and Virosome: the novel drug delivery system.UJPSR 2017; 3(1):24-33.

21. Sharma S. Novel drug delivery approach in cancer therapy. Journal of Pharmacy \& pharmaceutical Science 2016; 5(2):120125.

22. Moser C. Influenza virosomes applied in current and future vaccines. Virus like particle as vaccines 2017; 1-24. 